\title{
Crustal deformations in Kii peninsula associated with the SE off the Kii peninsula earthquake sequence of September 5, 2004 derived from dense GPS observations
}

\author{
Manabu Hashimoto, Kensuke Onoue, Fumio Ohya, Yoshinobu Hoso, Kohei Segawa, Kazutoshi Sato, and Yasuyoshi Fujita \\ Disaster Prevention Research Institute, Kyoto University, Uji 611-0011, Japan
}

(Received November 30, 2004; Revised March 4, 2005; Accepted March 5, 2005)

\begin{abstract}
We present crustal deformations in southern Kii peninsula, southwest Japan, before and after the SE off the Kii peninsula earthquake sequence of September 5, 2004, which were obtained from repeated surveys of dense GPS network. Disaster Prevention Research Institute (hereafter DPRI), Kyoto University made a reoccupation of their dense GPS network network that was occupied in February-March, 2004, right after the event to obtain crustal deformations associated with this event. Since we do not have the data just before the event, we apply an inversion of displacements of GEONET sites during the period from February-March to August, and interpolate displacements at DPRI's sites using the inverted fault model. Southward movements of about $2 \mathrm{~cm}$ are obtained in the middle of Kii peninsula, while displacements are rotated to southwest on the west side. These characteristics of horizontal displacement field cannot be explained only by a pure thrust faulting, but additional sources such as right-lateral faulting on a NW-SE trending fault are required.
\end{abstract}

Key words: SE off the Kii peninsula earthquakes, GPS, crustal deformation, fault model.

\section{Introduction}

On September 5, 2004, two earthquakes of M7.1 and 7.4 hit the central and southwest Japan. Hypocenters of these events are located SE off the Kii peninsula and right beneath the axis of the Nankai trough. The Tonankai earthquake of 1944 occurred between the hypocentral region of these events and Honshu Island. Aftershocks are aligned in two trends: one is parallel to the Nankai trough and the other is oblique to it. According to the observation with ocean bottom seismographs, the former is about $20 \mathrm{~km}$ deep and the latter is much shallower (Sakai et al., 2004). These events have almost pure thrust mechanism, but their $\mathrm{P}$ axes are in the NS direction that is different from the relative motion between the subducting Philippine Sea and overlying continental plates and nodal planes are very steep (National Institute for Earth Science and Disaster Prevention (hereafter NIED), 2004). However, some large aftershocks have nearly strike-slip fault mechanism. These strike-slip type aftershocks occurred along the oblique distribution to the Nankai trough.

DPRI, Kyoto University has been conducting dense GPS surveys in southern Kii peninsula in order to reveal the spatio-temporal variations in coupling between the subducting Philippine Sea and overriding plates since 2001 (Fig. 1). The Geographical Survey Institute (hereafter GSI) observed displacements associated with this sequence of earthquakes and showed southward to southwestward movements up to $2 \mathrm{~cm}$ in this region (GSI, 2004). This coseismic movement

Copy right(c) The Society of Geomagnetism and Earth, Planetary and Space Sciences (SGEPSS); The Seismological Society of Japan; The Volcanological Society of Japan; The Geodetic Society of Japan; The Japanese Society for Planetary Sciences; TERRAPUB. may greatly affect the estimate of average interseismic velocities. Furthermore postseismic movements might be expected. Therefore we decided to reoccupy our network in order to obtain coseismic and postseismic movements for the precise estimate of average velocity field.

\section{Observation}

We established a dense GPS network consisting of 9 sites in 2000. All sites are located on the roof of reinforced concrete buildings. A site (FUSI) with a $3 \mathrm{~m}$ tall stainless pillar was established in 2001. Furthermore, a site (SENK) with a $1.5 \mathrm{~m}$ tall stainless pillar was also established in 2002 . The location of these sites is shown in Fig. 1 as well as GEONET (GPS Earth Observation Network System, operated by GSI) sites. Basically, DPRI sites except SENK are occupied every March since 2001 in order to minimize seasonal variations. The last survey was made during the period from February 24 to March 9, 2004. Dual frequency receivers have been used to obtain precise positions of all sites.

Right after the occurrence of the SE off the Kii peninsula earthquakes, we reoccupied these sites in order to detect coseismic and postseismic movements. Observation started on September 7 and lasted till October 25, 2004. In this report, we present data till September 14 and discuss only coseismic motion due to the limitation of space. We will discuss postseismic deformation in a separate paper. We used the same sets of receiver and antenna in this campaign as much as possible, but equipments were replaced during the campaign at some sites due to the arrangements with other observation campaigns. We adopted the standard observation scheme for static continuous observation: Data 


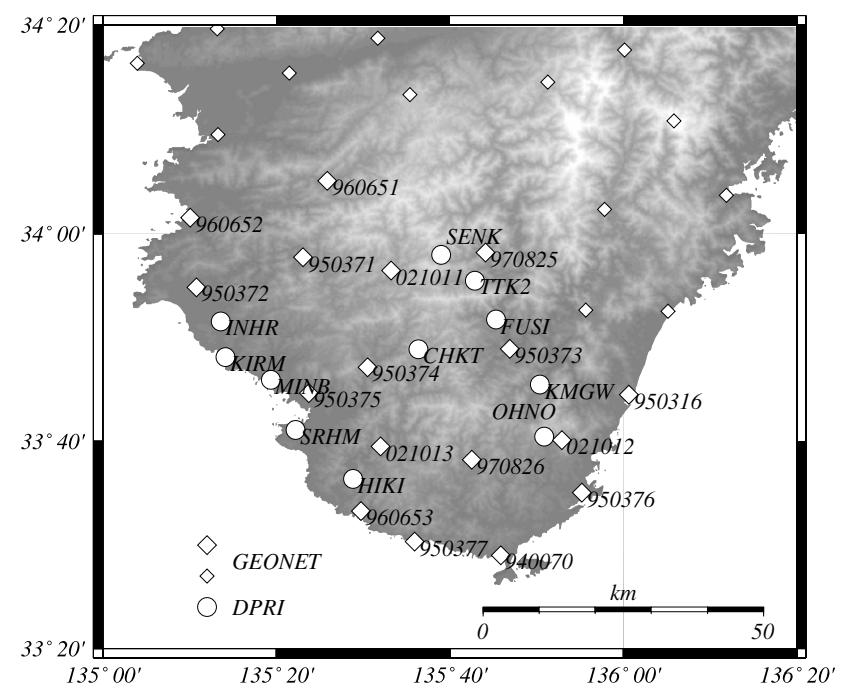

Fig. 1. Location of GPS observation sites in Kii peninsula. Open circles and diamonds show DPRI and GEONET sites, respectively. GEONET sites used in this research are indicated by large diamonds.

were sampled every 30 seconds. Elevation cut-off was 15 degree.

\section{Data Processing}

We adopt the standard static positioning for 24 hour data. Phase data from selected GEONET sites are also processed together with our data. We use GIPSY/OASIS II for the data processing of observed phase data. Precise ephemeredes and earth rotation parameters produced by the Jet Propulsion Laboratory (hereafter JPL) are also used. Precise point positioning is adopted and then ambiguities are fixed. Reference frame is ITRF2000. Due to the limitation of array size for ambiguity fixing in GIPSY we separate all stations into three groups and analyze them separately. We also use Helmert transformation parameters provided by JPL. Unfortunately there was a change in the analysis of Helmert transformation parameters by JPL since this April, which results in systematic shift of estimated coordinates since then. Obtained displacements are transformed from ITRF2000 to the Amurian plate reference frame. This procedure can be accomplished by using the Euler poles of Eurasia plate relative to no-net-rotation frame in NUVEL-1A (DeMets et al., 1994) and Amurian-Eurasia plate by Heki et al. (1999).

\subsection{Observed movements}

Figure 2 shows temporal variations in horizontal components of station coordinates in ITRF2000 during the period from 2001 to 2004. It is clearly seen that most stations had been moving at nearly constant rates till March, 2004 except for several stations such as SRHM, KIRM etc. The complicated variations in coordinates at these stations can be attributed to replacement of antenna. The correction parameters for the replacement of antennas can be obtained only by the observation at each site with two kinds of receivers. Unfortunately this kind of observation has not been done yet, since several receivers are unavailable due to other campaign. We are going to do this in near future. Large changes occurred at every station during the period from
February-March to August-September, 2004. This is the effect of difference in Hermert transformation parameters. Small steps between August and September, which can be seen in only GEONET stations, are coseismic deformations associated with the SE-off the Kii peninsula earthquake sequence. Up to $2 \mathrm{~cm}$ southward movements are recognized at stations in the middle of Kii peninsula such as 970825 and 950316. On the other hand, westward motions are observed at stations on the west side of Kii peninsula such as 940070 and 950375. Postseismic deformations can be recognized according to the results of analysis of data till Oct. 25, but we focus on coseismic movements in this preliminary report. For that purpose, we present only the results of coordinate estimation till September 11. Furthermore, we will not discuss vertical movements either, since vertical deformations larger than observation error cannot be expected according to the report by GSI (2004). Figure 3 shows the obtained horizontal displacements during the period from February-March to the next week of the occurrence of earthquakes. We simply take average coordinates of stations for each campaign and calculate their differences. Westward shift of $20 \mathrm{~mm}$ or larger is prevailing in the entire region, but their magnitude is much larger than that expected from the subduction for half a year. For the comparison, we show displacements at GEONET sites during the period of February-March to right before the earthquakes (Fig. 4). WNW-ward displacements are dominant, but their magnitude is still larger than the effect of subduction. As mentioned above, we attribute part of these large displacements to the effect of systematic difference in Helmert transformation parameters. In Fig. 3, we can recognize slightly southward rotation of displacements from those in Fig. 4, which can be related to the earthquakes. Since observation was not made at our sites just before the occurrence of earthquakes, changes in coordinates between February-March and September contain coseismic changes, secular motion for half a year and effects of shift in Helmert transformation parameters. We will extract coseismic changes from the observed changes using interpolation of displacement field before the earthquake in the next section.

\subsection{Interpolation of displacement field}

As mentioned in the previous chapter, there is a systematic shift in coordinates due to the difference in the Helmert transformation parameters. Therefore displacements that are obtained by direct comparison of coordinates in March and September include artificial movements. Furthermore they also include secular motion for half a year due to the subduction of the Philippine Sea plate. In order to eliminate these disturbances, we obtain coordinates of GEONET sites during the last two weeks before the earthquake with the same procedure as in the previous section, calculate their displacements for half a year, and interpolate displacements at our sites during the period from February-March to August using the obtained displacements of GEONET sites. Unfortunately, branches of trees that had shaded the antenna were cut during this period at two GEONET sites $(950372,960652)$ at the northwestern corner of the network, and there may be apparent coordinate shifts. These effects cannot be modeled, so that we use 9 sites excluding 

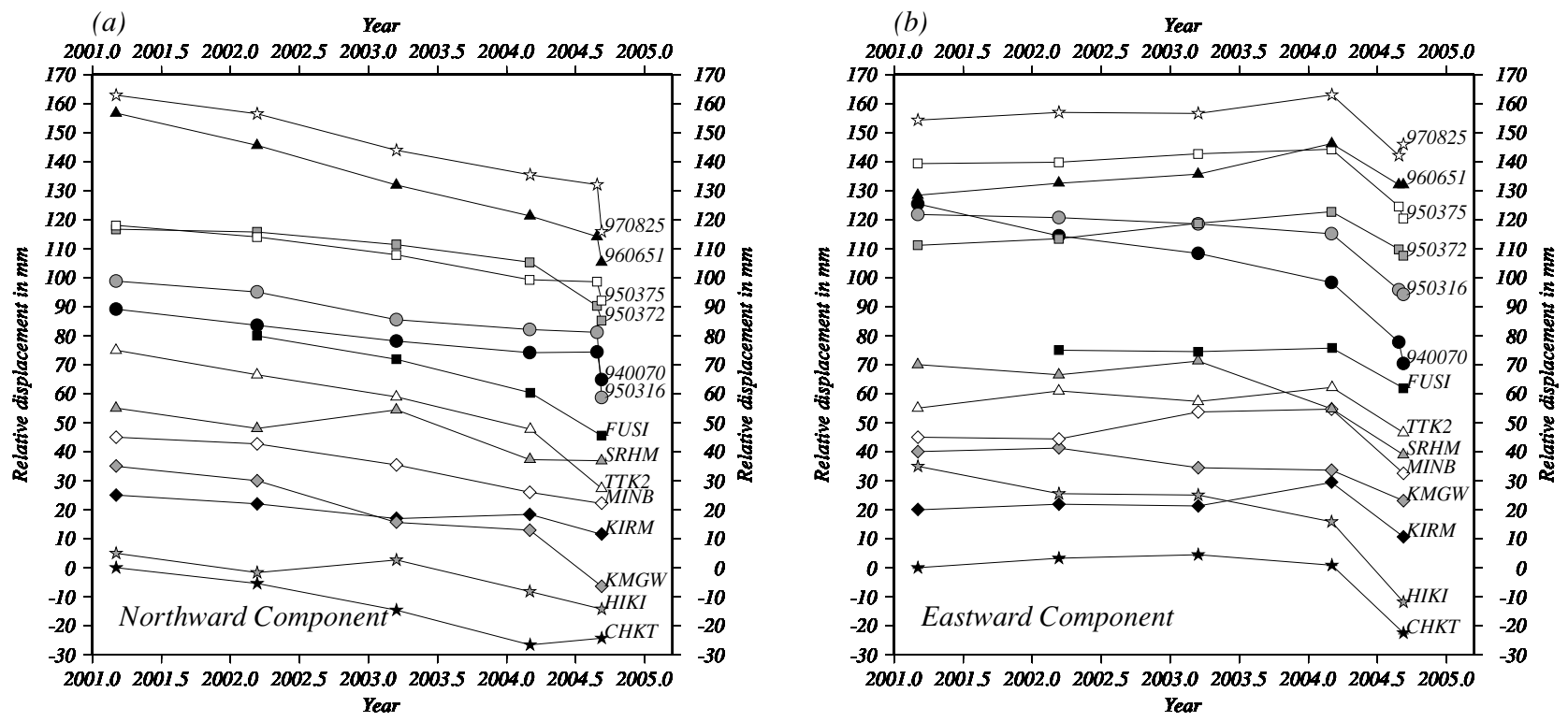

Fig. 2. Relative displacements in horizontal coordinates of GPS sites during the period from 2001 to 2004. (a) northward component, (b) eastward component.

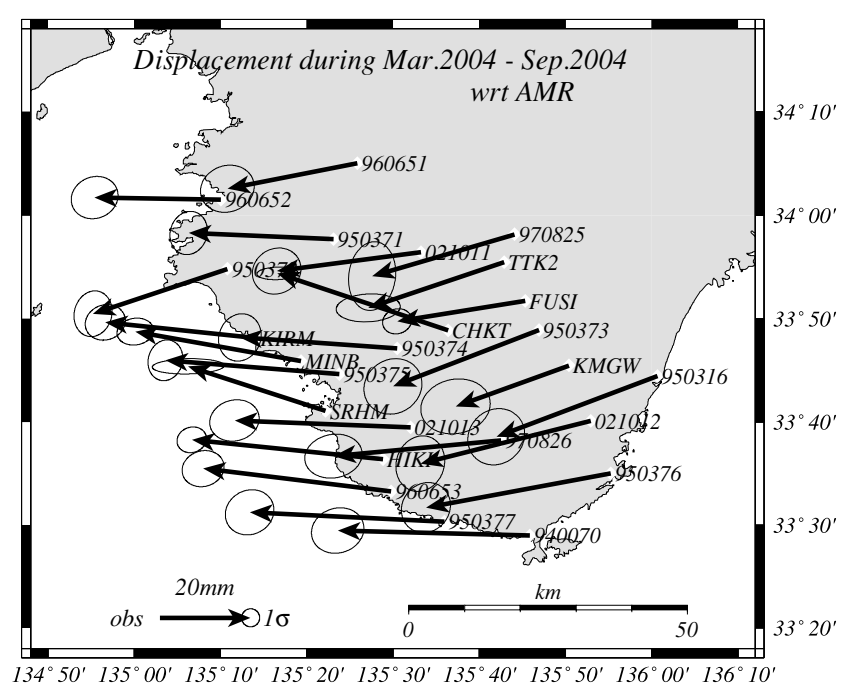

Fig. 3. Horizontal displacements during the period from February-March, 2004 to the next week to the earthquake sequence in September, 2004. Displacements are referred to the stable Amurian plate.

these two sites in the interpolation. Finally, we estimate coseismic displacements of our sites by subtracting interpolated displacements from observed ones during the period from February-March to September.

For the interpolation of displacement field, we use dislocation model (e.g. Okada, 1992). Secular deformations are simulated well by dislocation model, in which slip or slip deficit rates are estimated on the interface of subducting and overlying plates (e.g. Miyazaki and Heki, 2001). We use 9 segments beneath Kii peninsula in Sagiya and Thatcher (1999) and three deeper extensions, because other segments may not contribute to the displacement field there so much. First, we try to fit the fault model to the observed displacements. North-south components are fit fairly well, but eastwest components have systematic deviations according to

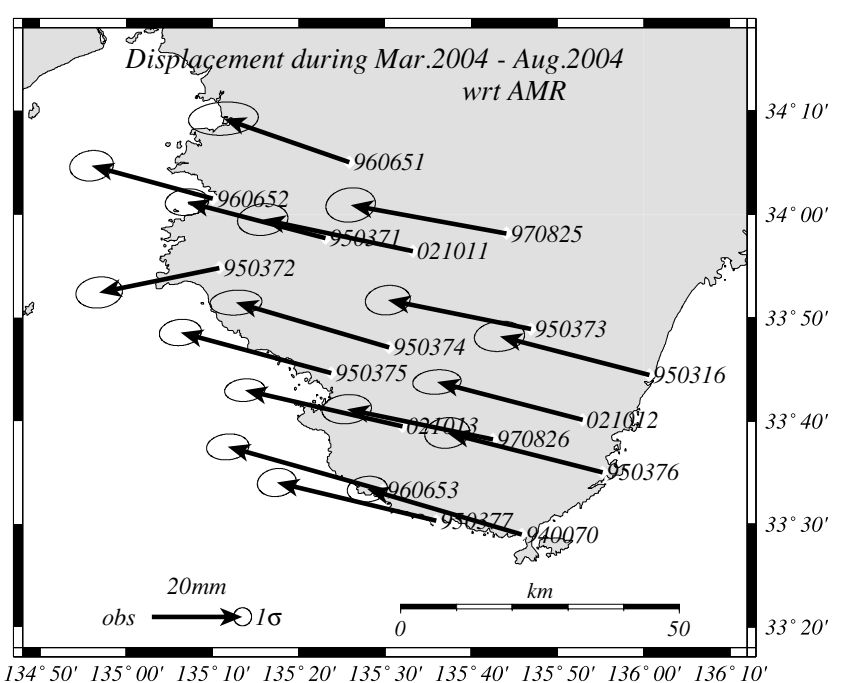

Fig. 4. Same as Fig. 3 but for the period from February-March, 2004 to weeks before the earthquake sequence.

latitude. Observed E-W components are larger than those simulated in the north of the network, and vice versa. These residual components can be regarded as rigid rotation components due to artificial shift of Helmert transformation parameters. If we plot the residual of EW components against the latitude of each site, we can find a correlation (Fig. 5), simply fit a regression line, and predict rigid components at our sites. Then, we subtract residual from the original observed displacement and estimate a fault model. Figure 6 shows the observed and simulated displacements as well as the estimated "virtual slip" during the period from March to August. Please notify this "virtual slip" has no physical meaning, since the observed displacements include secular motions and artificial shifts due to the difference in the frame for Helmert transformation parameters. Finally we interpolate displacements of our sites with the disloca- 


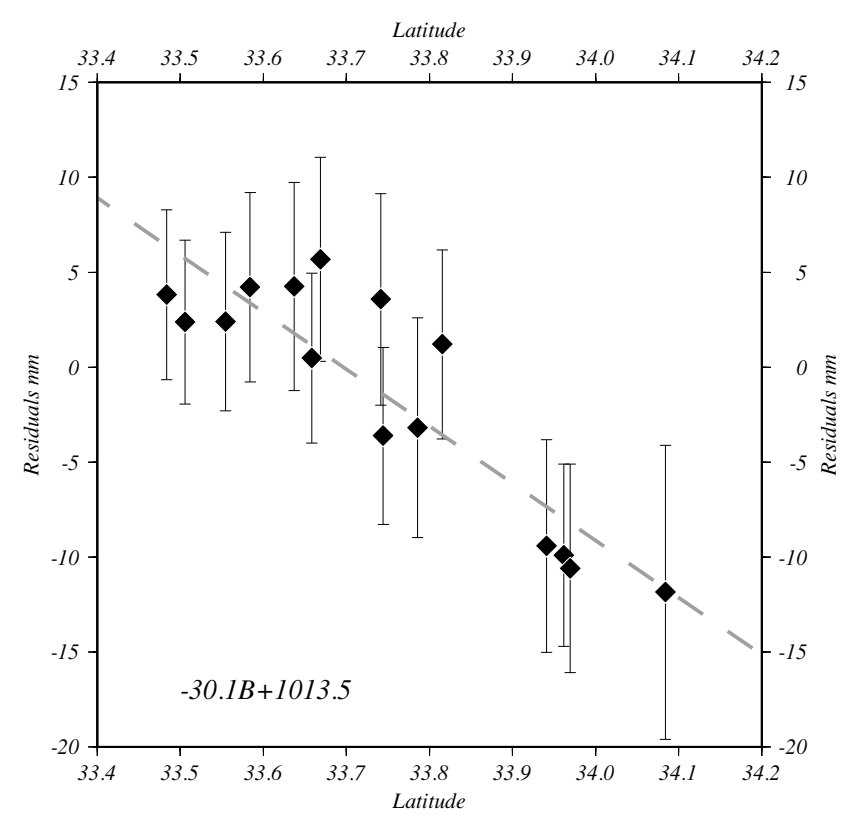

Fig. 5. Residuals in observed and calculated eastward displacements at each station versus station latitude. Calculated displacements are obtained from the best-fit fault model to the observed horizontal displacements before the earthquake sequence in Fig. 4.

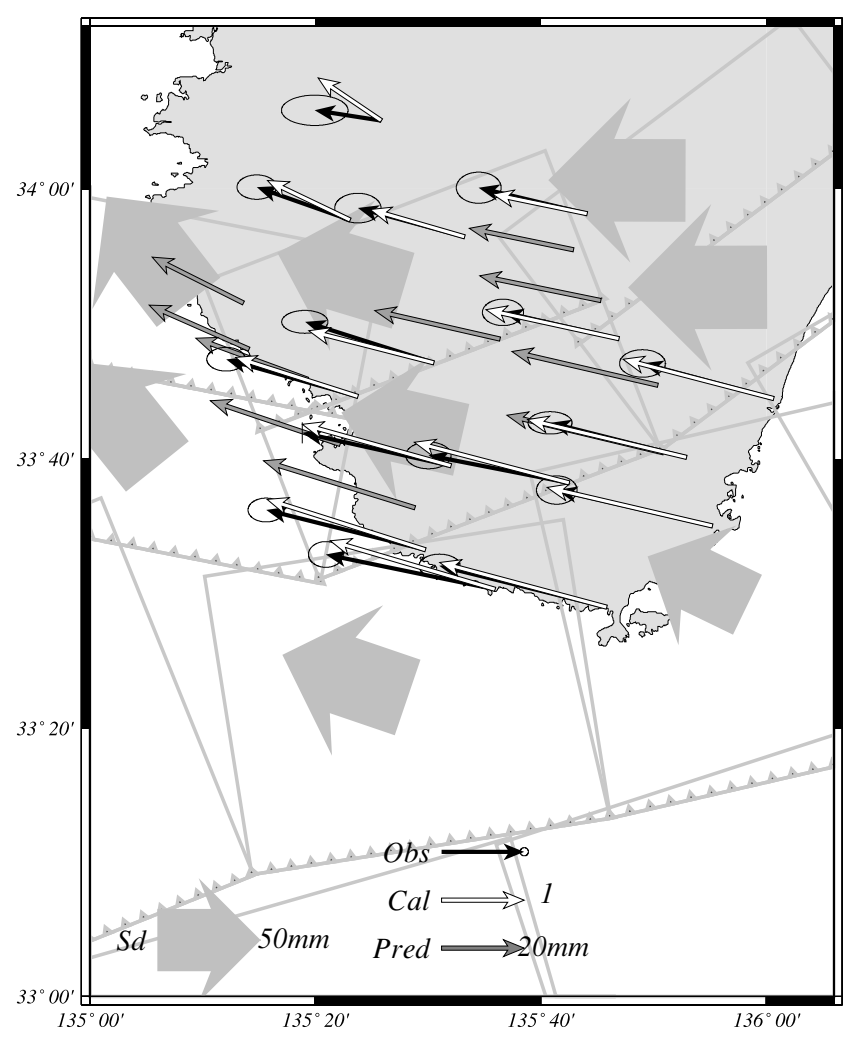

Fig. 6. Comparison between the observed displacements (black arrows) and the calculated ones (white arrows) before the earthquake sequence. Gray arrows show displacements predicted at DPRI's stations. Thick gray arrows indicate estimated "virtual slips" on fault segments.

tion model with 12 segments and linear relationship of E-W components between residuals and latitude (Fig. 4). Coseismic displacements at our sites are estimated by subtracting the above interpolated displacements from the observed

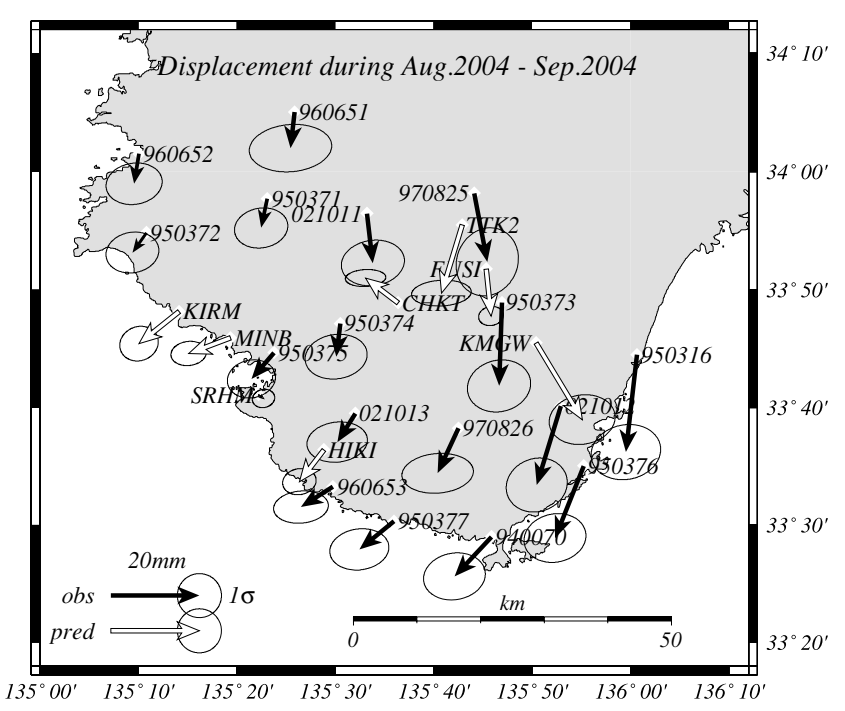

Fig. 7. Observed displacements at GEONET sites and corrected ones at DPRI's sites for the period from August to September, 2004. Displacements are referred to the stable Amurian plate.

ones during February-March to September.

\subsection{Crustal deformations before and after the SE off the Kii peninsula earthquake}

Figure 7 shows thus estimated coseismic displacements in Kii peninsula relative to the stable part of the Amurian plate. Southward movements of about $2 \mathrm{~cm}$ are prevailing in the eastern part of the network, while southwestward movements with smaller magnitude are dominant in the western part. Interseismic motion is $\mathrm{NW}$ to $\mathrm{WNW}$ and larger in the western part than in the eastern part (e.g. Miyazaki and Heki, 2001; Hashimoto et al., 2004). Therefore the present coseismic motion must be significantly different from those expected from the slip on the interplate faults.

Displacement vectors are rotated clockwise from east to west. Figure 8 shows the comparison of observed and calculated displacements for fault models, which is referred to the Yagi's (2004) two segment model, using Okada's (1992) formula. Parameters are listed in Table 1. Ohya (2004) compared theoretical strain steps for several fault models and concluded Yagi's model can explain observed strain steps best. This model consists of an EW trending thrust fault and a NW-SE trending vertical fault with right lateral slip. Since the CMT solution of the main shock is of almost pure thrust type (e.g. NIED, 2004), we calculated displacements for the E-W trending thrust fault only at first. However the observed and calculated displacement fields are quite different from each other (Fig. 8(a)). When we added a NW-SE trending right-lateral fault, characteristics of displacements at our sites are consistent with those for theoretical displacement field (Fig. 8(b)). Therefore we can conclude that observed displacements are explained by a pure thrust faulting on an E-W trending plane and a rightlateral strike-slip on a NW-SE trending plane.

A couple of our sites have inconsistent movements with that at surrounding stations. KMGW has a remarkable eastward component, but it can be attributed to a large estimation error in the September campaign. Displacements 

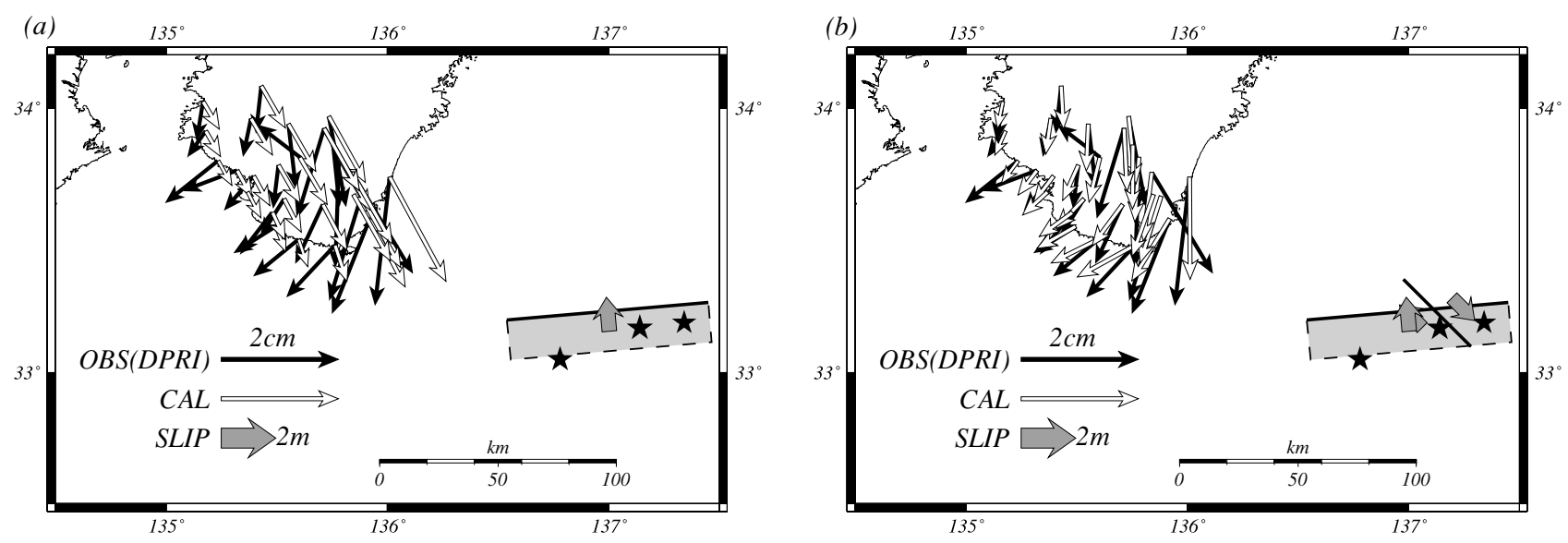

Fig. 8. Comparison of obtained displacementswith those calculated for the fault model modified from Yagi (2004). Theoretical displacements are calculated for (a) one thrust fault model and (b) combined model of thrust and vertical right-lateral slip faults. Black and white arrows show observed and calculated displacements, respectively. Shaded rectangle and thick solid line show assumed fault segments. The former is thrust, while the latter is vertical fault with right lateral slip. Thick gray arrows show the horizontal projection of slip vectors of faults. Stars show epicenters of foreshock, mainshock and the largest aftershock determined by NIED (2004).

Table 1. Fault parameters modified from Yagi (2004).

\begin{tabular}{ccccccccc}
\hline Lat. $(\mathrm{deg})$ & Lon. $(\mathrm{deg})$ & $\mathrm{L}(\mathrm{km})$ & $\mathrm{W}(\mathrm{km})$ & $\mathrm{H}(\mathrm{km})$ & Strike $(\mathrm{deg})$ & Dip $(\mathrm{deg})$ & Rake $(\mathrm{deg})$ & $\mathrm{U}(\mathrm{m})$ \\
\hline 33.10 & 137.28 & 40 & 25 & 5 & 315.0 & 90.0 & 150.0 & 1.36 \\
33.20 & 136.54 & 85 & 22 & 10 & 85.0 & 40.0 & 90.0 & 1.62 \\
\hline
\end{tabular}

Lat. and Lon. denotes latitude and longitude of a corner of fault. L, W, and H are length, width and depth of the upper margin of fault in km. Strike is measured clockwise from the north. $\mathrm{U}$ is slip in $\mathrm{m}$.

at SRHM and CHKT are not concordant with those at surrounding stations, either. Replacement of antennas at CHKT may cause this discrepancy. However the same antenna was used in both campaigns in February-March and September at SRHM. We must investigate this cause further.

\section{Discussions}

The main characteristics of the coseismic displacement field are the southward movements in the eastern part of Kii peninsula and the Tokai area, and southwestward shifts in the western part of Kii peninsula (GSI, 2004). Most earthquakes have pure thrust mechanisms (e.g. NIED, 2004). However we cannot explain this displacement field only with thrust fault, which causes mostly SSE-ward motion. Therefore we need other sources that generate westward motion. Several researchers have presented fault models on the basis of teleseismic waves, strong motions, tsunami and displacement field obtained by continuous GPS (e.g. Yamanaka, 2004; Yagi, 2004; GSI, 2004; Hara, 2005; Baba et al., 2005; Satake et al., 2005). There are large discrepancies among their models. For example, Yamanaka (2004) proposed a NW-SE trending fault for the main shock, while Yagi (2004) and GSI (2004) prefer an E-W trending fault plane. Yagi's (2004) model has a NW-SE trending fault with right lateral slip, while GSI (2004) assumes a thrusting with a slight left lateral slip on an E-W trending fault. These two models generate similar displacement fields. Furthermore it is hard to determine the dip direction of faults, since the detailed aftershock distribution has not been obtained yet. Due to remote location of observation stations, it is difficult to precisely determine the source fault, since the displacement field on land does not have so much difference.

Ohya (2004) found large compressions in south Kii peninsula on the basis of continuous observations of crustal strain. A rise of water level was also reported in Hongu town, where GEONET 950373 and FUSI of our network are located (Sato et al., 2004). These sites are located in the area of rotation of displacement vectors derived from GPS observation. Southward displacements decrease abruptly there, which may deduce N-S contraction. We think these characteristics are very important in the discussion of source fault and any model must explain these phenomena.

In this report, we interpolated displacements at sites where observation was not made just before the earthquake sequence, by using GEONET data, and obtained consistent displacements with those at GEONET sites directly deduced from continuous observations. Spatial interpolations are usually made with algebraic functions such as spline or trigonometric functions, but these functions require many grid points. On the other hand, elastic Green function we used can provide better approximation with less number of "elements" than these functions. This idea is the same as the boundary element method. We think this idea of interpolation using dislocation can be applied to the results of regional campaigns of GPS surveys.

\section{Conclusions}

We conducted a campaign survey of GPS in southern Kii peninsula right after the occurrence of the SE off the Kii 
peninsula earthquake sequence of September 5, 2004 and obtained coseismic deformations. Since the last survey of the network was made in February-March, 2004, we did an interpolation of displacements of our sites till August using displacements of nearby GEONET sites and a dislocation model. This interpolation works well and southward movements of about $2 \mathrm{~cm}$ were obtained in the middle of Kii peninsula. On the west side of this peninsula displacements were rotated to southwest and their magnitude was decreased. These characteristics of horizontal displacement field cannot be explained only by a pure thrust faulting, but additional sources such as right-lateral faulting on a NW-SE trending conjugate fault are required.

Acknowledgments. The authors thank to Drs. Roland Bürgmann and Satoshi Miura for their comments which help improve the manuscript. We would like to thank Dr. Hiroaki Takahashi from Hokkaido University, who provided equipments for the urgent campaign survey in September. We also express sincere thankfulness to the people in Wakayama and Nara, who gave us permission to use there properties for our research. We thank the Geographical Survey Institute who provided us with GEONET data. We use the Generic Mapping Tools ver. 3.3.4 (Wessel and Smith, 1998) to prepare illustrations.

\section{References}

Baba, T., P. Cummins, and T. Hori, Fault geometry of the 2004 off the Kii peninsula earthquake inferred from offshore pressure waveforms, Earth Planets Space, 57, this issue, 161-166, 2005.

DeMets, C., R. G. Gordon, D. F. Argus, and S. Stein, Effect of recent revisions to the geomagnetic reversal time scale on estimates of current plate motions, Geophys. Res. Lett., 21, 2191-2194, 1994.

Geographical Survey Institute, The earthquake SE off Kii peninsula on September 5, in the summary of the 159 meeting of the Coord. Com. Earthq. Pred., http://cais.gsi.go.jp/YOCHIREN/JIS/159/index159.html, 2004.

Hara, T., Change of the source mechanism of the main shock of the 2004 off the Kii peninsula earthquakes inferred from long period body wave data, Earth Planets Space, 57, this issue, 179-183, 2005.

Hashimoto, M., F. Ohya, K. Onoue, Y. Hoso, K. Sato, and Y. Fujita,
Interplate coupling derived from the GPS traverse across the hinge-line in Kii peninsula, Prgr., Abstr. Seismol. Soc. Jpn. 2004 Fall Meeting, P042, 2004

Heki, K., S. Miyazaki, H. Takahashi, M. Kasahara, F. Kimata, S. Miura, N. F. Vasilenko, A. Ivashchenko, and K.-D. An, The Amurian plate motion and current plate kinematics in eastern Asia, J. Geophys. Res., 104, 29147-29155, 1999.

Miyazaki, S. and K. Heki, Crustal velocity field of southwest Japan: subduction and arc-arc collision, J. Geophys. Res., 106, 4305-4326, 2001.

National Institute for Earth Science and Disaster Prevention, Special issue on Off Kii peninsula earthquake of September 5, 2004 , http://www.hinet.bosai.go.jp/topics/se-off-kii0409/, 2004.

Ohya, F., Strain Step at the Earthquakes off the Southeast coast of Kii Peninsula on Sep. 5, 2004, Observed by Extensometers and the Fault Models, Rep. Coord. Com. Earthq. Pred., 2004 (submitted).

Okada, Y., Internal deformation due to shear and tensile faults in a halfspace, Bull. Seismol. Soc. Amer., 82, 1018-1040, 1992.

Sagiya, T. and W. Thatcher, Coseismic slip resolution along a plate boundary megathrust: The Nankai Trough, southwest Japan, J. Geophys. Res., 104, 1111-1129, 1999.

Sakai, S., T. Yamada, M. Shinohara, H. Hagiwara, T. Kanazawa, K. Obana, S. Kodaira, and Y. Kaneda, Urgent aftershock observation of the 2004 Off the Kii peninsula earthquake using ocean bottom seismometers, Earth Planets Space, 2004 (submitted).

Sato, T., N. Matsumoto, Y. Kitagawa, N. Koizumi, M. Takahashi, Y. Kuwahara, H. Ito, A. Cho, T. Satoh, and K. Ozawa, Changes in groundwater level associated with the 2004 Off Kii-Peninsula earthquakes (in preparation).

Satake, K., T. Baba, K. Hirata, S. Iwasaki, T. Kato, S. Koshimura, J. Takenaka, and Y. Terada, Tsunami source of the 2004 off the Kii Peninsula earthquakes inferred from offshore tsunami and coastal tide gauges, Earth Planets Space, 57, this issue, 173-178, 2005.

Wessel, P. and W. H. F. Smith, New improved version of the Generic Mapping Tools released, EOS Trans. AGU, 79, 579, 1998.

Yagi, Y., On the earthquakes that occurred southeast off Kii peninsula on September 5, 2004, http://iisee.kenken.go.jp/staff/yagi/eq/ Japan20040905/Japan20040905_1-j.html, 2004.

Yamanaka, Y., Reanalysis of the main shock of SE of Kii peninsula earthquake of September 5, http://www.eri.u-tokyo.ac.jp/sanchu/Seismo Note/2004/EIC153.html, 2004.

M. Hashimoto (e-mail: hasimoto@rcep.dpri.kyoto-u.ac.jp), K. Onoue, F. Ohya, Y. Hoso, K. Segawa, K. Sato, and Y. Fujita 